\title{
Patient Selection for Transarterial Chemoembolization in Hepatocellular Carcinoma: Importance of Benefit/Risk Assessment
}

\author{
Fabio Piscaglia ${ }^{a}$ Sadahisa Ogasawara ${ }^{b}$ \\ a Unit of Internal Medicine, Department of Medicinal and Surgical Sciences, University of \\ Bologna, S. Orsola Malpighi Hospital, Bologna, Italy; ${ }^{b}$ Department of Gastroenterology, \\ Graduate School of Medicine, Chiba University, Chiba, Japan
}

\section{Keywords}

Hepatocellular carcinoma · Regorafenib · Sorafenib · Transarterial chemoembolization

\begin{abstract}
Background: Liver cancer is the second most common cause of cancer-related death, with hepatocellular carcinoma (HCC) accounting for most primary liver cancers and most commonly arising from a history of advanced chronic liver disease. Among the available therapies, transarterial chemoembolization (TACE) is the most widely utilized and is considered the firstline treatment recommended for patients staged as intermediate HCC (Barcelona Clinic Liver Cancer stage B). If applied correctly, TACE can produce survival benefits without adversely affecting hepatic functional reserve. Summary: The aim of this nonsystematic review is to evaluate the evidence supporting TACE, with a special interest in intermediate HCC, for which this treatment is recommended in first line. However, intermediate HCC represents a broad and heterogeneous group of patients, not all of whom will benefit from TACE. This review highlights the importance of appropriate patient selection for initial TACE and for retreatment. It also evaluates evidence for the treatment of patients who become refractory to TACE. Some patients may, in fact, benefit from early switch (i.e., after 1 or 2 TACE treatments) to systemic therapies rather than continuing retreatments with TACE in order to preserve liver function, thus allowing sequential first- and second-line drug therapies. Key Messages: Careful assessment of an individual patient's benefit/risk ratio is recommended before any TACE session is considered to ensure optimal long-term outcomes in intermediate HCC.
\end{abstract}




\section{Liver Cancer}

\section{Introduction}

Primary liver cancer is currently the second most common cause of cancer-related death worldwide [1], and hepatocellular carcinoma (HCC) accounts for more than $90 \%$ of primary liver cancers [2], making it a key therapeutic target. The Barcelona Clinic Liver Cancer (BCLC) staging system [3] is widely applied for tumor characterization and to evaluate key factors influencing long-term prognosis. The BCLC system can, therefore, help facilitate appropriate patient selection for specific therapeutic interventions $[2,4,5]$. Nevertheless, the management of patients with HCC remains challenging. It is often complicated by the heterogeneity of the disease, the presence of underlying advanced liver disorders, and the need to coordinate a multidisciplinary health-care team comprising hepatologists, diagnostic and interventional radiologists, transplant surgeons, pathologists, and medical and surgical oncologists [5].

Transarterial chemoembolization (TACE), a locoregional therapy (LRT), is widely recommended as first-line treatment for intermediate-stage HCC (BCLC stage B) [2, 4]. Surgical resection, percutaneous ablation, and liver transplantation are also occasionally applied in highly selected BCLC stage B patients. The oral multikinase inhibitor sorafenib is the current standard systemic therapy for advanced HCC (BCLC stage C) or for those tumors progressing on LRT and is therefore an additional option for intermediate-HCC stage patients as first-line systemic treatment $[2,4]$. Recently, another multikinase inhibitor, regorafenib, was approved as second-line treatment for patients with HCC who had radiological progression under sorafenib, providing improved overall survival compared with placebo (hazard ratio [HR] 0.63 ; 95\% confidence interval [CI] 0.50-0.79; $p<0.0001$ ) with a median 2.8-month survival benefit $[6,7]$. Correct patient selection for treatment within BCLC stage B is therefore crucial to maximize response and survival, but this is not a trivial process, as choices in real-world settings may not match evidence-based recommendations [8].

\section{Objective}

The aim of this article is to review the efficacy, safety, and limitations of TACE in HCC, with a specific focus on the importance of appropriate patient selection, including the identification of patients whose disease becomes refractory to repeated treatments with TACE, and the potentially detrimental consequences of inappropriate TACE application on liver function and long-term clinical outcomes. In addition, we discuss the recommended administration and timing of systemic therapies as an alternative to or sequential to TACE.

\section{Benefits of TACE in Intermediate HCC}

TACE is the most widely used treatment for unresectable HCC that, if applied correctly, can produce survival benefits and favorable response without adversely affecting hepatic functional reserve [7]. In brief, conventional TACE is performed through the injection of chemotherapy mixed with Lipiodol (ethiodized oil), followed by the obstruction of a preselected hepatic artery branch that feeds the tumor. As HCC derives up to the totality of its blood supply from the hepatic artery, differently from the non-tumor liver parenchyma, occlusion primarily results in ischemic necrosis and slows tumor progression [9].

Further advances in TACE techniques include the introduction of microcatheterization of peripheral arterial branches with the aim of improving therapeutic selectivity, balloonoccluded TACE to increase therapeutic effect, and the use of drug-eluting beads (DEB-TACE) to improve drug delivery. Other avenues being explored include combination therapy with 


\section{Liver

TACE and other treatments, and immune therapy. Several reviews have described these advances in detail $[9,10]$. Based on the increased heterogeneity of the TACE approach, a clearer algorithm for patient selection would be of great importance.

Several trials have compared TACE with conservative management or suboptimal therapies (such as chemotherapy with 5-fluorouracil or oral tamoxifen) in HCC (see online suppl. Table 1; for all online suppl. material, see www.karger.com/doi/10.1159/000485471) [1119]. Although the findings from these trials were rather heterogeneous, meta-analyses have confirmed an overall survival benefit of TACE $[20,21]$. One meta-analysis of randomized controlled trials assessed the survival benefit of arterial embolization/chemoembolization in 6 trials reporting 2-year survival and 1 trial reporting 1-year survival in a total of 545 patients [20]; 2-year survival was 41\% (range 19-63\%) in the treatment group and 27\% (range $11-50 \%$ ) in the control group. The odds ratio for 2-year survival favored chemoembolization (odds ratio $=0.53 ; 95 \% \mathrm{CI} 0.32-0.89 ; p=0.017$ ). The treatment-induced objective response (complete or partial response lasting 1-6 months) was 35\% (range 16-61\%). Based on the inclusion criteria of these trials and the outcomes, the authors concluded that patients with well-preserved liver function and multinodular HCC without vascular invasion were the best target population for TACE. However, the treatment effect was modest, the ranges for survival and objective response (a predictor of survival) were large, and not all patients responded to therapy. Furthermore, the trials were not designed for patient selection. A more recent systematic review with data from more than 10,000 patients with HCC undergoing TACE found that the objective response was $52.5 \%$, while overall survival was $70.3 \%$ at 1 year, $51.8 \%$ at 2 years, $40.4 \%$ at 3 years, and $32.4 \%$ at 5 years [21]. These findings are in line with those reported previously. However, a Cochrane analysis of 6 trials found no survival benefit of TACE over control, emphasizing the need for more adequately powered trials [22]. This meta-analysis was criticized primarily due to the lack of focus on trials, including the correct profile for TACE (i.e., BCLC stage B patients with compensated liver disease) [23]. This highlights the controversy surrounding patient recruitment for TACE, but also that the use of TACE in intermediate HCC should not be automatic [24].

\section{Guideline Recommendations}

Based on currently available evidence, international guidelines and consensus working groups have published general guidance on the use of TACE; recommendations for the use of TACE in intermediate HCC are listed in Table 1 [2, 4, 25-29]. In general, TACE is regarded as the standard of care for patients with intermediate HCC (BCLC stage B) who have wellpreserved liver function and large or multinodular HCC without portal vein tumor thrombosis or extrahepatic metastasis $[2,4,25]$. The guidelines estimate that $\sim 20 \%$ of all HCC patients are the target population for TACE, and the median overall survival in patients who receive TACE is 20 months (range 14-45 months) [2]. TACE achieves partial responses in $15-55 \%$ of patients and delays tumor progression and macrovascular invasion [2]. Some expert centers apply stricter patient selection for TACE [30]. When only very fit intermediatestage HCC patients with perfectly preserved liver function undergo TACE, expected survival may be up to 48 months [30], but stricter selection also implies that fewer patients are receiving LRTs, particularly borderline-compensated patients. Some or most of these patients may be candidates for systemic treatment, as they are unfit for resective or locoregional therapies that affect liver function.

\section{Considerations between Western and Asian Populations}

There are several epidemiological differences in HCC across geographical regions, as well as differences in genetic mutations, especially between Western and Asian populations [31, 32]. The incidence of HCC is considerably higher in Asian countries, such as China and 
Piscaglia and Ogasawara: Patient Selection for Transarterial Chemoembolization in Hepatocellular Carcinoma: Importance of Benefit/Risk Assessment

Table 1. Key guideline-based recommendations and contraindications for the use of TACE in intermediate HCC

\begin{tabular}{|c|c|c|c|c|}
\hline Region & Guideline & Recommendations & Contraindications & $\begin{array}{l}\text { Gray areas for patient selection } \\
\text { and outcomes }\end{array}$ \\
\hline $\begin{array}{l}\text { United } \\
\text { States }\end{array}$ & AASLD [4] & $\begin{array}{l}\text { First-line in nonsurgical } \\
\text { intermediate stage (Child-Pugh A) } \\
\text { patients with large multifocal HCC } \\
\text { who do not have cancer-related } \\
\text { symptoms, macrovascular invasion, } \\
\text { or extrahepatic spread } \\
\text { Nonsurgical patients ineligible for } \\
\text { percutaneous ablation who do not } \\
\text { have extrahepatic spread }\end{array}$ & $\begin{array}{l}\text { Patients with lack of portal } \\
\text { blood flow, lobar or segmental } \\
\text { (acute or chronic) portal vein } \\
\text { thrombosis, portosystemic } \\
\text { anastomoses or hepatofugal } \\
\text { flow }\end{array}$ & $\begin{array}{l}\text { Objective response (a } \\
\text { predictor of survival) is } \\
\text { variable } \\
\text { Lack of criteria to ensure that } \\
\text { ischemic necrosis is prevented } \\
\text { in viable liver }\end{array}$ \\
\hline \multirow[t]{3}{*}{ Europe } & $\begin{array}{l}\text { EASL-EORTC } \\
{[2]}\end{array}$ & $\begin{array}{l}\text { First-line in BCLC stage B, } \\
\text { multinodular asymptomatic tumors } \\
\text { without vascular invasion or } \\
\text { extrahepatic spread in Child-Pugh A } \\
\text { or selected B7 patients }\end{array}$ & $\begin{array}{l}\text { Decompensated liver disease, } \\
\text { or advanced liver dysfunction, } \\
\text { macroscopic vascular invasion } \\
\text { or extrahepatic spread }\end{array}$ & $\begin{array}{l}\text { Outcome prediction is } \\
\text { heterogeneous for BCLC } \\
\text { stage B }\end{array}$ \\
\hline & $\begin{array}{l}\text { ESMO-ESDO } \\
{[25]}\end{array}$ & $\begin{array}{l}\text { BCLC stage B, or in patients with an } \\
\text { excellent liver function and } \\
\text { multinodular asymptomatic tumors } \\
\text { without vascular invasion or } \\
\text { extrahepatic spread }\end{array}$ & $\begin{array}{l}\text { Decompensated cirrhosis, } \\
\text { extensive tumor with massive } \\
\text { replacement of both entire } \\
\text { lobes, severely reduced portal } \\
\text { vein flow, untreatable } \\
\text { arteriovenous fistula, } \\
\text { bilioenteric anastomosis or } \\
\text { biliary stents, and a creatinine } \\
\text { clearance }<30 \mathrm{~mL} / \mathrm{min}\end{array}$ & $\begin{array}{l}\text { Magnitude of benefit } \\
\text { dependent on technique used } \\
\text { and patient characteristics } \\
\text { Outcomes less favorable with } \\
\text { increasing size and number of } \\
\text { lesions }\end{array}$ \\
\hline & AISF [29] & $\begin{array}{l}\text { First line in patients with large, } \\
\text { multifocal, unresectable tumors in } \\
\text { the absence of macrovascular } \\
\text { invasion and extrahepatic spread } \\
\text { (BCLC stage B); the best candidates } \\
\text { are asymptomatic Child-Pugh A } \\
\text { patients, although those with } \\
\text { Child-Pugh B7 can be considered; } \\
\text { TACE can be utilized in patients with } \\
\text { early-stage HCC if surgical or } \\
\text { ablative techniques are not } \\
\text { applicable due to technical } \\
\text { conditions and/or comorbidities }\end{array}$ & $\begin{array}{l}\text { Jaundice, untreatable ascites, } \\
\text { main or portal vein } \\
\text { thrombosis, hepatofugal portal } \\
\text { blood flow, HCC nodules }>10 \\
\mathrm{~cm}\end{array}$ & $\begin{array}{l}\text { TACE may be considered in } \\
\text { patients with large masses } \\
\text { and/or portal thrombosis/ } \\
\text { invasion, but prospective trials } \\
\text { aimed at ascertaining its cost- } \\
\text { effectiveness profile are } \\
\text { required }\end{array}$ \\
\hline \multirow[t]{2}{*}{ Asia } & APASL [26] & $\begin{array}{l}\text { First line in patients with } \\
\text { unresectable, large multifocal HCCs } \\
\text { without vascular invasion or } \\
\text { extrahepatic spread } \\
\text { Selective TACE can be performed in } \\
\text { patients with small tumors in whom } \\
\text { RFA is difficult to perform } \\
\text { Selective TACE should be attempted } \\
\text { in order to preserve liver } \\
\text { parenchyma, maximize treatment } \\
\text { effect, and minimize complications } \\
\text { Other treatment strategies might be } \\
\text { considered for patients with HCC } \\
\text { who are not suitable or do not } \\
\text { respond to repeated TACE }\end{array}$ & & $\begin{array}{l}\text { There is no standardized } \\
\text { protocol for TACE in terms of } \\
\text { treatment schedule or type and } \\
\text { dosage of anticancer agent } \\
\text { There is no agreement on the } \\
\text { degree of embolization } \\
\text { There is no consensus on the } \\
\text { definition of TACE } \\
\text { refractoriness }\end{array}$ \\
\hline & $\mathrm{JSH}[27]$ & $\begin{array}{l}\text { First line in nonsurgical intermediate } \\
\text { stage (Child-Pugh A and B) } \\
\text { May also be considered for patients } \\
\text { with Child-Pugh A and vascular } \\
\text { invasion }\end{array}$ & - & - \\
\hline
\end{tabular}


Piscaglia and Ogasawara: Patient Selection for Transarterial Chemoembolization in Hepatocellular Carcinoma: Importance of Benefit/Risk Assessment

Table 1 (continued)

\begin{tabular}{|c|c|c|c|c|}
\hline Region & Guideline & Recommendations & Contraindications & $\begin{array}{l}\text { Gray areas for patient selection } \\
\text { and outcomes }\end{array}$ \\
\hline Asia & KLCSG [28] & $\begin{array}{l}\text { Nonsurgical patients with good } \\
\text { performance status without major } \\
\text { vascular invasion or extrahepatic } \\
\text { spread } \\
\text { In case of portal vein invasion, TACE } \\
\text { can be considered in patients with } \\
\text { localized tumor and well-preserved } \\
\text { liver function } \\
\text { Prior to transplantation (if the } \\
\text { timing is not predictable) or for } \\
\text { downstaging }\end{array}$ & - & $\begin{array}{l}\text { Remission rate may depend on } \\
\text { size and number of tumors, } \\
\text { and pattern of tumor growth } \\
\text { Future trials should explore } \\
\text { survival benefits in patients } \\
\text { with unfavorable prognostic } \\
\text { factors such as poor } \\
\text { performance status, major } \\
\text { portal vein tumor invasion, } \\
\text { Child-Pugh C, and extrahepatic } \\
\text { metastasis }\end{array}$ \\
\hline
\end{tabular}

AASLD, American Association for the Study of Liver Diseases; AISF, Italian Association for the Study of the Liver; APASL, Asian Pacific Association for the Study of the Liver; BCLC, Barcelona Clinic Liver Cancer; EASL-EORTC, European Association for the Study of the Liver-European Organisation for Research and Treatment of Cancer; ESMO-ESDO, European Society for Medical Oncology-European Society of Digestive Oncology; HCC, hepatocellular carcinoma; JSH, Japan Society of Hepatology; KLCSG, Korean Liver Cancer Study Group; RFA, radiofrequency ablation; TACE, transarterial chemoembolization.

Southeast Asia, and in Africa, compared with Europe and North America [33]. In 2012, 50\% of new HCC cases occurred in China [33]. A key epidemiological difference is the fact that HCC in most Asian countries (e.g., China and Southeast Asia) primarily results from hepatitis B virus (HBV) infection, whereas in Japan and Western countries, hepatitis C virus (HCV) infection is the primary risk factor for HCC $[31,32]$. As HBV-related HCC may occur in patients with or without cirrhosis, a higher proportion of Asian patients are noncirrhotic. Moreover, many Asian and less developed countries do not have nationwide HCC surveillance programs, so patients often have advanced disease at diagnosis or intermediate-stage HCC with large tumor bulk, differing from intermediate-stage HCC discovered during surveillance or recurring after treatments of early-stage HCC. During the development of the Hong Kong Liver Cancer (HKLC) staging system in patients with HCC primarily resulting from HBV infection, the median age of patients was 58 years, $36.6 \%$ had locally advanced disease, and $13.2 \%$ had extrahepatic invasion [34]. In Japan, where HCC primarily arises from HCV infection, there is a nationwide surveillance program, so patients are diagnosed at an earlier stage of disease [31]. Moreover, Japanese patients tend to be older when diagnosed. The mean age at diagnosis of Japanese patients has increased from approximately 60 to 70 years over the past 30 years, in part because of the increased life expectancy of the Japanese population [35]. These differences in characteristics between Asian patients and Western patients, and between Asian patients from different countries (e.g., China vs. Japan), may affect the selection of treatment strategies.

There are few randomized controlled trials evaluating TACE in Asian populations. In one randomized controlled trial [15] in Asian patients with unresectable HCC, actuarial survival was significantly improved with TACE compared with symptomatic treatment (57\% vs. $32 \%$ at year $1,31 \%$ vs. $11 \%$ at year 2 , and $26 \%$ vs. $3 \%$ at year $3 ; p=0.002$ ). In 3 nonrandomized trials (in China and South Korea), TACE significantly improved overall survival compared with conservative management at year 1 (see online suppl. Table 1) [17-19]. The majority of patients in these trials had hepatitis B, and patients with portal vein thrombosis were included in 2 trials. In a noncontrolled trial in 8,510 patients with HCC from Japan, overall survival with initial TACE was $26 \%$ at year 5 . However, this trial included patients with both early- and intermediate-stage HCC [36]. 


\section{Liver Cancer}

\begin{tabular}{l|l}
\hline Liver Cancer 2018;7:104-119 & $\begin{array}{l}\text { ( 2018 S. Karger AG, Basel } \\
\text { www.karger.com/lic }\end{array}$ \\
\hline DOI: 10.1159/000485471
\end{tabular}

Piscaglia and Ogasawara: Patient Selection for Transarterial Chemoembolization in Hepatocellular Carcinoma: Importance of Benefit/Risk Assessment

A number of Asian-based societies have produced treatment guidelines similar to those published by societies from the United States and Europe (Table 1). However, the Japan Society of Hepatology recommends that TACE be considered also in patients with Child-Pugh A and vascular invasion [27], and the Asian Pacific Association for the Study of the Liver (APASL) guidelines recommend TACE as a treatment option regardless of whether patients have macrovascular invasion [26], which is a major difference from US/European guidelines. Consequently, patients with HCC and macrovascular invasion often receive TACE in Asian countries.

There are also differences between Asian and US/European approaches to HCC staging, with some staging systems deemed more appropriate for Asian versus non-Asian populations [31]. For example, the HKLC staging system appears to be more suitable for Asian patients than the BCLC system. Based on an analysis of data from 3,856 patients with HCC, the ability to predict overall survival was significantly greater with the HKLC than the BCLC classification [34]. Notably, the HKLC system identified subsets of BCLC intermediate- and advancedstage patients who would benefit from more aggressive treatment, and the 5-year survival benefit of radical treatments was substantial compared with TACE in BCLC stage B (HKLC-II) patients $(52.1 \%$ vs. $18.7 \% ; p<0.0001)$. A similar benefit of the HKLC system over the BCLC system was observed in a trial of 668 patients with HCC from China [37]. Both trials acknowledged that differences in etiology (e.g., hepatitis B onset) between Asian and European patients may account for this. Validation of the HKLC system in non-Asian cohorts was not successful in a single study [38]; further studies are warranted.

\section{Complications and Contraindications of TACE}

In the systematic literature review described previously [21], 21,461 adverse events (including complications and toxicities) were reported in 15,351 patients undergoing 27,497 TACE treatments. The most common adverse events were related to the postembolization syndrome, and included liver enzyme abnormalities (18.1\%), fever (17.2\%), abdominal pain $(11.0 \%)$, vomiting $(6.0 \%)$, and nausea (1.7\%). Recently, the incidence of postembolization syndrome was shown to be reduced by a short course of steroids [39], but external validation and effects on oncological outcomes in larger populations with longer follow-up are required before such prophylaxis can be fully endorsed [40]. Hematological/bone marrow toxicity occurred in $13.5 \%$ of patients. A total of 214 deaths were reported in 34,137 patients, for an overall mortality rate of $0.6 \%$. The most common cause of death was related to acute liver insufficiency. Hence, current treatment-related death is estimated to be less than $1 \%$ in patients with HCC.

The major contraindications for TACE in the recent guidelines are listed in Table 1. These include decompensated cirrhosis (Child-Pugh $\mathrm{B} \geq 8$, including jaundice, clinical encephalopathy, refractory ascites, and hepatorenal syndrome), and severely reduced portal vein blood flow (acute and chronic portal vein thrombosis or hepatofugal blood flow) [25, 41]. Other absolute contraindications include extensive tumor involving the entirety of both liver lobes; technical contraindications, such as untreatable arteriovenous fistula; renal insufficiency, including creatinine $\geq 2 \mathrm{mg} / \mathrm{dL}$ or creatinine clearance $<30 \mathrm{~mL} / \mathrm{min}$; and bilioenteric anastomosis or biliary stents [25]. Relative contraindications include factors related to liver cirrhosis (untreated varices at high risk of bleeding), tumor size $(\geq 10 \mathrm{~cm})$, severe comorbidities (acute cardiovascular or lung disease), and bile duct occlusion [41]. Of note, European guidelines list macroscopic vascular invasion as a contraindication; however, the APASL guidelines note that Asian patients with macroscopic invasion (but no extrahepatic metastasis) are often treated with TACE, despite limited scientific evidence supporting this practice 
Piscaglia and Ogasawara: Patient Selection for Transarterial Chemoembolization in

Hepatocellular Carcinoma: Importance of Benefit/Risk Assessment

[26]. Similarly, the HKLC treatment algorithm states that patients with extrahepatic vascular invasion are unsuitable for TACE [34]. The Japan Society of Hepatology guidelines state that TACE may be considered for patients with Child-Pugh A and vascular invasion, but chemotherapy is recommended [27].

\section{Addressing Limitations of TACE: Patient Selection and Prognosis}

Guidelines acknowledge that the limitations of TACE are primarily due to the heterogeneity within the population and the difficulty in extracting evidence from the literature [2, 25]. Available data are also confounded by a wide range of treatment approaches, including differences in emulsifying agents and heterogeneity with respect to outcome prediction and degree of selectivity in treatment delivery $[2,5]$. Thus, because of these factors, not all intermediate HCC patients will derive similar benefit from or are suitable candidates for TACE. Intermediate-stage HCC patients present with varying tumor burdens, liver function, and disease etiology, and some patients may benefit from alternative treatment options [42]. An overview of the key factors for patient selection in TACE is shown in Figure 1 [3, 27, 34, 43-47].

\section{Staging Systems}

Staging systems such as the Okuda [48], BCLC, Child-Pugh, HKLC, Japan Tumor-NodeMetastasis (TNM), and the Cancer of the Liver Italian Program (CLIP) $[49,50]$ have been widely applied and validated in numerous trials for prognosis prediction. There have also been attempts to combine systems; for example, the Japan Integrated Staging (JIS) score combines Child-Pugh and TNM. This approach was found to be more prognostic compared with CLIP; 10 -year survival rates were 23\% (CLIP score 0 group) and $65 \%$ (JIS score 0 group) $(p<0.01)$ [51]. Very few staging systems connect stages with both prognosis and treatment allocation. As there are variations between different systems, staging tailored to specific etiologies may produce more accurate treatment strategies and survival predictions [52]. However, some systems are not consistent across all stages; for example, CLIP was more discriminating in early (score 0-3) than later (score 4-6) disease stages [51]. Survival was also found to be better when patients received recommended treatment in stages HKLC I, IIa/b, IIIa, or Va than in stages IIIb, IVa/b, or $\mathrm{Vb}$, and when patients received recommended treatment in BCLC stages 0 or A, but not in stages B, C, or D. In addition, neither system (HKLC or BCLC) could direct therapy for a large group of patients [53].

The heterogeneity of patients with intermediate HCC (BCLC stage B) means that not all patients may benefit from TACE [7]. This has led to the division of BCLC stage B into 4 subclassifications (B1, B2, B3, and B4), based on tumor burden and liver function, and representing increasing severity of disease. In this scenario, TACE is proposed as first-line therapy for patients who are categorized as B1 or B2, and as a potential option in the B3 subgroup, but not for those in the B4 subgroup [54]. A modification of this subclassification (Kinki criteria) into 3 groups (B1, B2, and B3) has been proposed by Japanese investigators [55].

\section{Other Selection Criteria}

TACE is the theoretical first-line therapy for intermediate HCC patients, but in practice it may not be the most appropriate therapy in all patients. Other selection criteria for treatment in intermediate HCC include simplification of earlier systems, such as the Chiba HCC in intermediate-stage prognostic (CHIP) score, which is specific to patients with intermediate HCC undergoing TACE. This score identified and focused on the most prognostic factors using a dataset from the Chiba University Hospital, namely the number of lesions (producing scores 
Piscaglia and Ogasawara: Patient Selection for Transarterial Chemoembolization in

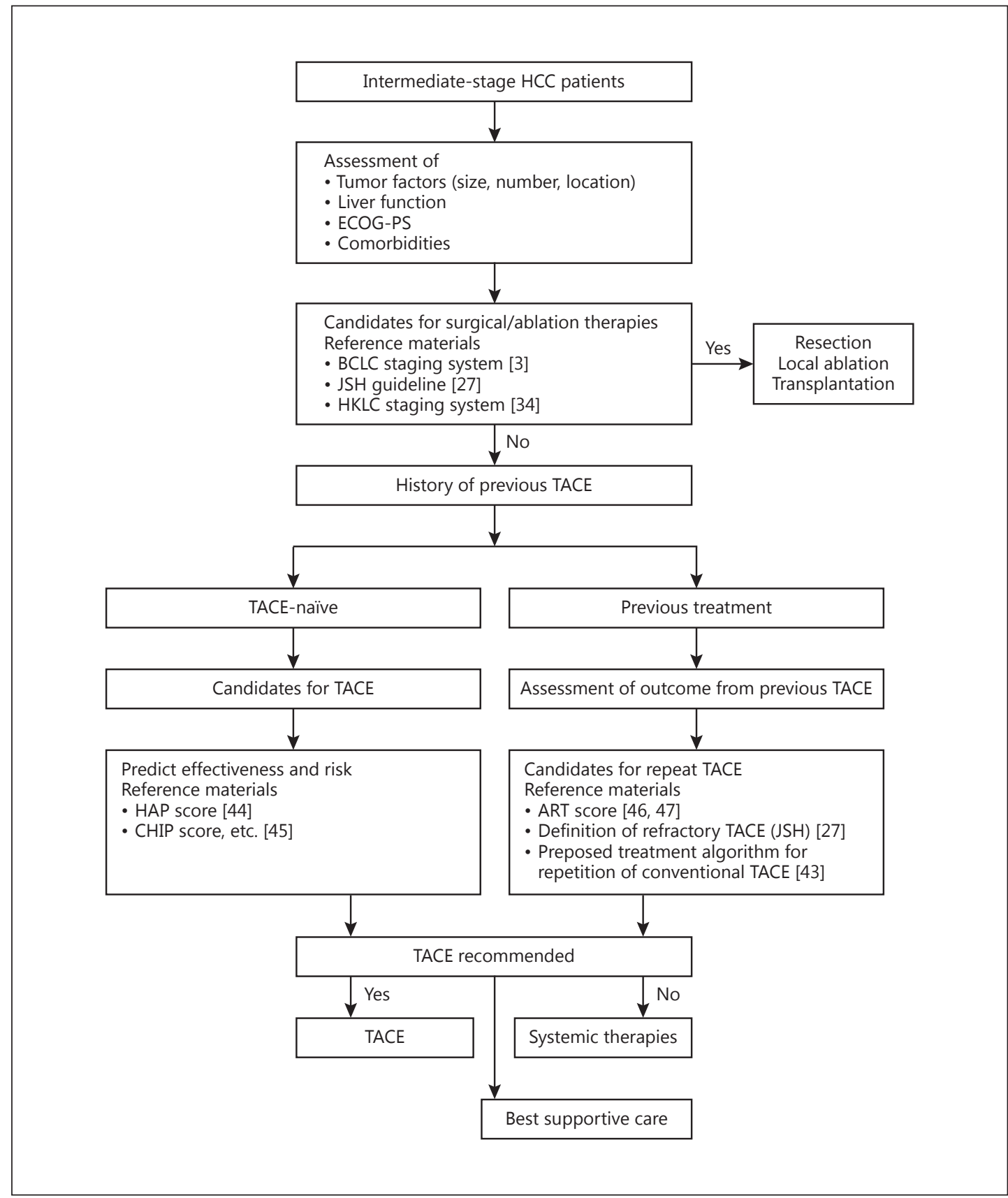

Fig. 1. Treatment selection process in patients with intermediate-stage HCC. ART, assessment for retreatment with TACE; BCLC, Barcelona Clinic Liver Cancer; CHIP, Chiba HCC in intermediate-stage prognostic; ECOG-PS, Eastern Cooperative Oncology Group performance status; HAP, hepatoma arterial-embolization prognostic; HCC, hepatocellular carcinoma; HKLC, Hong Kong Liver Cancer; JSH, Japan Society of Hepatology; TACE, transarterial chemoembolization.

of 0,2 , or 3), liver function categorized according to Child-Pugh system (scores 0-3), and HCV-RNA positivity ( 0 or 1 ), which was validated using an independent cohort from another hospital [45]. The generated CHIP scores were then differentiated into 5 groups $(0-2,3,4,5$, and 6-7 points) by median survival times $(65.2,29.2,24.3,13.1$, and 8.4 months). This 


\section{Liver Cancer}

\begin{tabular}{l|l}
\hline Liver Cancer 2018;7:104-119 \\
\hline DOI: 10.1159/000485471 & $\begin{array}{l}\text { C } 2018 \text { S. Karger AG, Basel } \\
\text { www.karger.com/lic }\end{array}$ \\
\hline
\end{tabular}

Piscaglia and Ogasawara: Patient Selection for Transarterial Chemoembolization in Hepatocellular Carcinoma: Importance of Benefit/Risk Assessment

approach could be used on a larger scale to stratify responders in more detail from randomized controlled trials and simplify the scoring approach.

Another validated prognostic scoring system is the hepatoma arterial-embolization prognostic (HAP) score, which is based on 4 factors that were found to be significant predictors of overall survival: albumin level, bilirubin level, $\alpha$-fetoprotein, and tumor size. A HAP score is the sum of points allocated to each factor, and patients are then classified into risk groups based on HAP score (low [HAP A] = 0 points; intermediate $[\mathrm{HAP} \mathrm{B]}=1$ point; high $[\mathrm{HAP} \mathrm{C}]=$ 2 points; very high [HAP D] $=>2$ points). The HAP score may be used to predict outcomes in patients being considered for TACE and guide treatment selection [44].

A recent prospective trial reported that lower serum albumin and increased tumor burden (larger tumor size/more nodules and higher $\alpha$-fetoprotein) at baseline may help predict hepatic decompensation in HCC patients following their first TACE treatment [56]. Similarly, recent evidence suggests that first TACE is more effective in HCC patients with nodules $<5 \mathrm{~cm}$, whereas those with nodules $>5 \mathrm{~cm}$ had poorer response rates and poorer outcomes [57]. Interrelated with the assessment of individual patient characteristics, centerspecific technical factors should also be considered when deciding if TACE is an appropriate therapy. These factors include the skill and experience of the radiologist, as well as the technique and materials (e.g., catheter size) available. Ongoing genomic and proteomic trials may also be useful for patient selection according to their molecular profile [32]; however, markers from such trials are not yet available. Other arterially directed therapies to consider include transarterial bland embolization, DEB-TACE, and transarterial radioembolization (TARE) with yttrium-90 microspheres [5].

\section{Treatment of Refractory Disease}

\section{Retreatment}

For patients whose disease is unresponsive or refractory to TACE, the main considerations for potential retreatment with TACE include a reassessment of the expected post-TACE survival outcomes versus risks. This decision may be guided by retreatment algorithms, such as the Assessment for Retreatment with TACE (ART) [46, 47], and the $\alpha$-fetoprotein, BCLC, Child-Pugh and Response (ABCR) [58] scores (Fig. 1). The ART score was developed based on a retrospective analysis in 222 patients with HCC (BCLC stage A or B and Child-Pugh A or B) treated at 2 Austrian centers who had received at least 2 sessions of TACE within 90 days. Using multivariate analyses, aspartate aminotransferase level increase of $>25 \%$ (absent vs. present), Child-Pugh score increase (absent vs. +1 point vs. $+\geq 2$ points), and radiological tumor response (absent vs. present) were found to be prognostic factors for overall survival. An ART score was determined based on these factors, and patients with a score of $\geq 2.5$ points before their second TACE session were found to have a shorter overall survival and a higher incidence of adverse events, so were considered to be unlikely to gain further benefit from further TACE [46]. The ABCR score uses 4 predictors of overall survival: $\alpha$-fetoprotein $<200$ vs. $\geq 200 \mathrm{ng} / \mathrm{mL}$ ) at baseline, BCLC (A vs. B vs. C) at baseline, Child-Pugh score increase (absent vs. +1 point vs. $+\geq 2$ points), and tumor response (absent vs. present) to determine a score ranging from -3 to +6 . The scoring system was developed using a multivariate analysis of a population of 133 patients with alcohol- or viral-induced HCC, and validated in 2 other cohorts of 78 and 100 patients. The ABCR score was calculated immediately before the second TACE session. A higher ABCR score was predictive of a poorer prognosis, and it was suggested that patients with a score $\geq 4$ would not benefit from further TACE treatment [58].

However, the predictive value of both of these scoring systems has been questioned. Several studies have reported that the ART score was not a useful tool for guiding decisions 


\section{Liver

on TACE retreatment. In an Italian retrospective analysis in 51 patients with HCC (BCLC stage A or B and Child-Pugh A or B), the ART score was not a significant predictor of survival [59]. A key difference between this study and the original ART score study was that patients may have had longer than 90 days between their first and second TACE, based on the clinical decision of the center. Furthermore, in a retrospective analysis of 627 Japanese patients with HCC (most with Child-Pugh A and BCLC stage B) who had received 2 or more TACE sessions, the ART score was found to be unsuitable for most patients, as only $12 \%$ had received their second TACE within 90 days. For these patients, the ART score did not predict overall survival [47]. This finding was also reported in a smaller Japanese retrospective study, where less than $10 \%$ of patients had their second TACE session within 90 days of the first, and the ART score did not predict outcomes in these patients [60]. These findings underscore regional and national differences in the approach to the use of TACE, as on-demand TACE is more common in Japan compared with Europe and the United States [47], and differences in TACE procedures, therapies administered after TACE, and timing between TACE sessions may affect the results when evaluating outcomes [60]. An external validation of both ART and ABCR in 176 patients with HCC (BCLC stage A or B and Child-Pugh A or B) who had received at least 2 TACE sessions found that while patients with higher scores had poorer prognoses, neither score had sufficient predictive ability to aid in clinical decision-making regarding subsequent TACE sessions [61].

Interestingly, in an international study in 83 patients from the UK and Italy and 660 patients from Korea and Japan with HCC (BCLC stage A or B), both scoring systems were found to be independently predictive of survival, and sequential use of the HAP score to screen patients for initial TACE and the ART score to determine the value of TACE retreatment was proposed [62].

It is important to note that ART and ABCR scores are not included in current treatment guidelines, so should be considered exploratory. Moreover, they do not measure responsiveness to TACE; rather, they are dynamic prognostic scores to measure treatment-related survival benefit based on radiological response, tumor markers, and hepatic function, and have not been universally validated.

\section{Systemic Therapy}

Repeated TACE is associated with increased adverse events (e.g., liver dysfunction) and diminishing efficacy $[41,43]$, which suggests that options other than retreatment should be considered. A few patients who achieved partial response could benefit from the addition of more aggressive therapies (such as radiofrequency ablation), which initially would have been contraindicated, to attempt to elicit a complete response. However, most patients tend not to achieve a satisfactory objective response, but progress or recur early after treatment. Unfortunately, time to TACE progression (TTTP) was recently shown to be a surrogate endpoint for overall survival, i.e. a short TTTP corresponds to a short overall survival with TACE. Therefore, alternative treatments, such as sorafenib, should be considered early in patients whose disease is refractory to TACE and/or with a short TTTP [63]. In fact, intermediate HCC patients whose disease was refractory to TACE who received sorafenib experienced an increase in survival compared with those who continued TACE in 2 retrospective trials from Japan. The median survival was 25.4 versus 11.5 months ( $p=0.003$ ) (first trial) [64] and 24.7 versus 13.6 months ( $p=0.002$ ) (second trial) [65].

Based on the beneficial effects of sorafenib on survival in patients with advanced HCC, several studies have investigated the efficacy and safety of combinations of TACE and sorafenib. In a meta-analysis of 17 studies evaluating TACE plus sorafenib combination therapy in patients with unresectable HCC, most of whom had Child-Pugh class A or B disease severity and BCLC stage B or C, the HR for time to progression (TTP) was 0.76 (95\% CI 0.66- 
0.89; $p<0.001$ ), suggesting that TACE plus sorafenib may improve TTP compared with TACE alone. However, the HR for overall survival was 0.81 (95\% CI 0.65-1.01; $p=0.061$ ), suggesting that the addition of sorafenib to TACE may not improve overall survival compared with TACE alone [66]. In a smaller meta-analysis of 6 studies in patients with intermediate or advanced HCC, most of whom had Child-Pugh class A disease, the pooled HR for TTP was 0.68 (95\% CI $0.52-0.88 ; p=0.003$ ), and for overall survival was 0.65 (95\% CI 0.47-0.89; $p=0.007$ ), indicating beneficial effects of TACE combined with sorafenib, although the incidence of grade 3 or 4 adverse events was also higher with the combination [67]. A recent European, randomized, double-blind, phase 3 trial (TACE 2) in 313 patients with unresectable HCC (Child-Pugh A) comparing sorafenib or placebo, both in combination with TACE, was stopped early because there was no difference in progression-free survival between groups. Median progressionfree survival was 238 days (95\% CI 221-281) in the sorafenib plus TACE group compared with 235 days (95\% CI 209-322) in the placebo plus TACE group (HR 0.99 [95\% CI 0.771.27], $p=0.94$ ). There was also no significant difference between treatment groups in TTP or overall survival [68]. Similar findings were reported for the international, phase 2, randomized, placebo-controlled SPACE trial of sorafenib plus TACE in 307 patients with intermediate HCC, with no significant difference in TTP between the combination group and the TACE-only group [69]. Overall, the evidence suggests that combination treatment is not beneficial, suggesting that a sequential approach may be preferred, i.e. use of TACE early, followed by systemic therapy before the onset of liver dysfunction.

Some intermediate HCC patients who are particularly fit and with optimal liver function may benefit from more aggressive treatments. In a retrospective analysis of 485 patients with intermediate HCC (BCLC stage B), treatment distribution was TACE (51.1\%), curative treatments (31.8\%), sorafenib (3.9\%), best supportive care (4.6\%), and other treatments $(8.5 \%)$ [70]. The median survival was 45 months for curative treatments, 30 months for TACE, 14 months for sorafenib, and 10 months for best supportive care. Although it is difficult to make direct comparisons due to differences in patient numbers, characteristics, and other prognostic factors, these findings indicate that there is a role for treatments other than TACE as initial therapy for BCLC stage B, although TACE and systemic therapies must be promptly adopted at the time of progression or recurrence after more aggressive approaches.

Recent data from the RESORCE trial showed that patients receiving regorafenib as second-line therapy after sorafenib failure in advanced HCC had a survival benefit of $\sim 2.8$ months compared with those receiving placebo. Median survival was 10.6 months in the regorafenib group compared with 7.8 months in the placebo group, with an HR of 0.63 ( $p<$ $0.0001)[6,7]$. Thus, other systemic therapies may become available with the potential to extend survival, provided that patients start systemic therapy after TACE failure when they are still compensated and fit [71]. With increasing treatment options now available beyond the singular use of TACE, health-care professionals should be encouraged to develop, in close collaboration with each patient, positive long-term individualized treatment plans focused on delaying disease recurrence and prolonging survival.

\section{Impact of TACE on Liver Function}

One of the key considerations for any treatment strategy in HCC is to preserve liver function as much as possible. Several trials have observed acute liver dysfunction in patients treated with TACE, especially with less selective or repeated TACE procedures $[64,65,72]$. In one retrospective trial [64], the median time to liver dysfunction in patients with refractory disease who continued to receive TACE was significantly shorter than in those who switched to sorafenib (29.8 months [95\% CI 21.7-38.0] vs. 17.0 months [95\% CI 8.3-25.7]; $p=0.030$ ). In another retrospective trial [65], repeated TACE in patients with refractory disease was associated with a greater increase in Child-Pugh score compared with that observed in 


\section{Liver Cancer}

\begin{tabular}{l|l}
\hline Liver Cancer 2018;7:104-119 \\
\hline DOI: 10.1159/000485471 & $\begin{array}{l}\text { @ 2018 S. Karger AG, Basel } \\
\text { www.karger.com/lic }\end{array}$ \\
\hline
\end{tabular}

patients who switched to sorafenib, indicating that repeated TACE may lead to deterioration in liver function in patients with refractory disease. These data support a timely switch to sorafenib therapy to prevent deterioration of liver function with inappropriate TACE use; this is critical for safe follow-on treatment with sorafenib. Liver dysfunction with sorafenib has also been occasionally reported, although the incidence is not significantly higher compared with placebo [73], and is usually reversible with drug discontinuation, in contrast to that emerging after TACE. With the recent approval of regorafenib, it will be increasingly important to critically monitor the treatment for HCC, so that when a patient's disease becomes refractory to TACE, the switch to sorafenib-regorafenib sequential therapy is performed in a timely manner [7].

\section{Conclusions}

TACE is recommended as first-line therapy in intermediate HCC (BCLC stage B) and, if applied correctly, both in terms of technical performance and patient selection, can produce survival benefits without adversely affecting hepatic functional reserve. However, the heterogeneity of patients with intermediate HCC means that not all patients with intermediate HCC may benefit from first-line therapy with TACE. TACE is often used in a broader population than is recommended by current guidelines, but the use of TACE should not only be determined by the technical feasibility of the procedure. A more tailored approach to patient selection for TACE may improve outcomes. The use of validated staging systems, identification of key prognostic factors, and consideration of patient characteristics, treatment benefit/risk profile, and limitations will help to balance the potential survival benefit against potential risks for adverse events. Some patients with intermediate HCC may benefit from a more aggressive initial approach, such as curative resection and/or ablation, particularly those with preserved liver function (Child-Pugh A, no portal hypertension, and BCLC stage B with limited tumor bulk). The "up-to-7" rule recommends transplantation for patients with BCLC stage B HCC if the sum of the size of the largest tumor (in centimeters) and the total number of tumors is $\leq 7$ [74]. For patients with intermediate HCC (Child-Pugh A) within the "up-to-7" classification and who are not candidates for resection plus ablation, or with clinically compensated liver function (BCLC score B7), TACE is still the standard of care. To further ensure the success of TACE in these patients, a stricter definition of tumor bulk may be valuable, beyond the "up-to-7" rule.

For patients with tumor bulk beyond the "up-to-7" classification and very well preserved liver function (Child-Pugh A5 or A6), the extent of tumor burden should be carefully evaluated. TARE may be recommended for patients beyond "up-to-7" threshold with greater tumor volumes (i.e., the largest tumors greater than 5-6 cm) and limited tumor numbers. If patients in this category are not suitable for TARE or TARE is not available, TACE may be an option (especially when tumor bulk is beyond the "up-to-7" threshold, but not excessively large). However, evidence of survival benefit is less clear in this setting, as there is the risk of not preserving liver function while attempting to achieve complete response. Consequently, initial systemic therapy is an alternative option to be considered. Patients whose disease is refractory to TACE or ineligible for LRT may benefit from systemic therapies, such as sorafenib followed by regorafenib in cases of radiological progression, or sequential therapy with TACE followed by sorafenib, although the efficacy of these combinations has yet to be confirmed in rigorous clinical trials. Further investigation of biomarkers that provide an objective means of patient selection for TACE, based on the likelihood that they will benefit from treatment, will provide much-needed guidance for clinicians. 
Piscaglia and Ogasawara: Patient Selection for Transarterial Chemoembolization in Hepatocellular Carcinoma: Importance of Benefit/Risk Assessment

In conclusion, careful assessment of an individual patient's benefit/risk ratio is recommended before any TACE session is considered. It is important to select the right treatment for the right patient at the right time to ensure optimal long-term outcomes in intermediate HCC.

\section{Acknowledgements}

Medical writing assistance was provided by Samantha Phillips, PhD, and Yvonne E. Yarker, PhD, of PAREXEL, which was funded by Bayer.

\section{Disclosure Statement}

Fabio Piscaglia is a consultant to Bayer and declares advisory fees from Bayer and Eisai, research contract with Esaote, and speakers bureau honoraria from Bayer and Bracco. Sadahisa Ogasawara is a consultant to Bayer and Eisai, and declares advisory fees and honoraria from Bayer and Eisai.

\section{References}

1 World Health Organization: Cancer: Fact Sheet (February 2017). http://www.who.int/mediacentre/factsheets/fs297/en/ (accessed May 5, 2017).

2 EASL-EORTC clinical practice guidelines: management of hepatocellular carcinoma. J Hepatol 2012;56:908943.

3 Llovet JM, Brú C, Bruix J: Prognosis of hepatocellular carcinoma: The BCLC Staging Classification. Semin Liver Dis 1999;19:329-338.

4 Bruix J, Sherman M: Management of hepatocellular carcinoma: an update. Hepatology 2011;53:1020-1022.

5 National Comprehensive Cancer Network: NCCN Clinical Practice Guidelines in Oncology. Hepatobiliary Cancers. Version 3.2017.

6 Bruix J, Qin S, Merle P, Granito A, Huang YH, Bodoky G, Pracht M, Yokosuka O, Rosmorduc O, Breder V, Gerolami R, Masi G, Ross PJ, Song T, Bronowicki JP, Ollivier-Hourmand I, Kudo M, Cheng AL, Llovet JM, Finn RS, LeBerre MA, Baumhauer A, Meinhardt G, Han G: Regorafenib for patients with hepatocellular carcinoma who progressed on sorafenib treatment (RESORCE): a randomised, double-blind, placebo-controlled, phase 3 trial. Lancet 2017;389:56-66.

7 Kudo M: Regorafenib as second-line systemic therapy may change the treatment strategy and management paradigm for hepatocellular carcinoma. Liver Cancer 2016;5:235-244.

8 Geschwind JF, Gholam PM, Goldenberg A, Mantry P, Martin RC, Piperdi B, Zigmont E, Imperial J, Babajanyan S, Foreman PK, Cohn A: Use of transarterial chemoembolization (TACE) and sorafenib in patients with unresectable hepatocellular carcinoma: US regional analysis of the GIDEON registry. Liver Cancer 2016;5:37-46.

$9 \mathrm{Au} \mathrm{JS}$, Frenette CT: Management of hepatocellular carcinoma: current status and future directions. Gut Liver 2015;9:437-448.

10 Imai N, Ishigami M, Ishizu Y, Kuzuya T, Honda T, Hayashi K, Hirooka Y, Goto H: Transarterial chemoembolization for hepatocellular carcinoma: a review of techniques. World J Hepatol 2014;6:844-850.

11 Lencioni R: Chemoembolization in patients with hepatocellular carcinoma. Liver Cancer 2012;1:41-50.

12 Pelletier G, Roche A, Ink O, Anciaux ML, Derhy S, Rougier P, Lenoir C, Attali P, Etienne JP: A randomized trial of hepatic arterial chemoembolization in patients with unresectable hepatocellular carcinoma. J Hepatol 1990;11:181-184.

13 A comparison of lipiodol chemoembolization and conservative treatment for unresectable hepatocellular carcinoma. GETCH (Groupe d'Etude et de Traitement du Carcinome Hépatocellulaire). N Engl J Med 1995;332: 1256-1261.

14 Pelletier G, Ducreux M, Gay F, Luboinski M, Hagege H, Dao T, Van Steenbergen W, Buffet C, Rougier P, Adler M, Pignon JP, Roche A: Treatment of unresectable hepatocellular carcinoma with lipiodol chemoembolization: a multicenter randomized trial. Groupe CHC. J Hepatol 1998;29:129-134.

15 Lo CM, Ngan H, Tso WK, Liu CL, Lam CM, Poon RT, Fan ST, Wong J: Randomized controlled trial of transarterial lipiodol chemoembolization for unresectable hepatocellular carcinoma. Hepatology 2002;35:1164-1171.

16 Llovet JM, Real MI, Montana X, Planas R, Coll S, Aponte J, Ayuso C, Sala M, Muchart J, Sola R, Rodes J, Bruix J: Arterial embolisation or chemoembolisation versus symptomatic treatment in patients with unresectable hepatocellular carcinoma: a randomised controlled trial. Lancet 2002;359:1734-1739. 
17 Luo J, Guo RP, Lai EC, Zhang YJ, Lau WY, Chen MS, Shi M: Transarterial chemoembolization for unresectable hepatocellular carcinoma with portal vein tumor thrombosis: a prospective comparative study. Ann Surg Oncol 2011;18:413-420.

18 Dai QS, Gu HL, Ye S, Zhang YJ, Lin XJ, Lau WY, Peng ZW, Chen MS: Transarterial chemoembolization versus conservative treatment for unresectable infiltrating hepatocellular carcinoma: a retrospective comparative study. Mol Clin Oncol 2014;2:1047-1054.

19 Song DS, Nam SW, Bae SH, Kim JD, Jang JW, Song MJ, Lee SW, Kim HY, Lee YJ, Chun HJ, You YK, Choi JY, Yoon SK: Outcome of transarterial chemoembolization-based multi-modal treatment in patients with unresectable hepatocellular carcinoma. World J Gastroenterol 2015;21:2395-2404.

20 Llovet JM, Bruix J: Systematic review of randomized trials for unresectable hepatocellular carcinoma: chemoembolization improves survival. Hepatology 2003;37:429-442.

21 Lencioni R, de Baere T, Soulen MC, Rilling WS, Geschwind JF: Lipiodol transarterial chemoembolization for hepatocellular carcinoma: a systematic review of efficacy and safety data. Hepatology 2016;64:106-116.

22 Oliveri RS, Wetterslev J, Gluud C: Transarterial (chemo)embolisation for unresectable hepatocellular carcinoma. Cochrane Database Syst Rev 2011;CD004787.

23 Forner A, Llovet JM, Bruix J: Chemoembolization for intermediate HCC: is there proof of survival benefit? J Hepatol 2012;56:984-986.

24 Farinati F, Giacomin A, Vanin V, Giannini E, Trevisani F: TACE treatment in hepatocellular carcinoma: what should we do now? J Hepatol 2012;57:221-222.

25 Verslype C, Rosmorduc O, Rougier P: Hepatocellular carcinoma: ESMO-ESDO clinical practice guidelines for diagnosis, treatment and follow-up. Ann Oncol 2012;23(suppl 7):vii41-vii48.

26 Omata M, Cheng AL, Kokudo N, Kudo M, Lee JM, Jia J, Tateishi R, Han KH, Chawla YK, Shiina S, Jafri W, Payawal DA, Ohki T, Ogasawara S, Chen PJ, Lesmana CRA, Lesmana LA, Gani RA, Obi S, Dokmeci AK, Sarin SK: AsiaPacific clinical practice guidelines on the management of hepatocellular carcinoma: a 2017 update. Hepatol Int 2017;11:317-370.

27 Kokudo N, Hasegawa K, Akahane M, Igaki H, Izumi N, Ichida T, Uemoto S, Kaneko S, Kawasaki S, Ku Y, Kudo M, Kubo S, Takayama T, Tateishi R, Fukuda T, Matsui O, Matsuyama Y, Murakami T, Arii S, Okazaki M, Makuuchi M: Evidence-based clinical practice guidelines for hepatocellular carcinoma: the Japan Society of Hepatology 2013 update (3rd JSH-HCC Guidelines). Hepatol Res 2015;45.

282014 Korean Liver Cancer Study Group-National Cancer Center Korea practice guideline for the management of hepatocellular carcinoma. Korean J Radiol 2015;16:465-522.

29 Bolondi L, Cillo U, Colombo M, Craxi A, Farinati F, Giannini EG, Golfieri R, Levrero M, Pinna AD, Piscaglia F, Raimondo G, Trevisani F, Bruno R, Caraceni P, Ciancio A, Coco B, Fraquelli M, Rendina M, Squadrito G, Toniutto P: Position paper of the Italian Association for the Study of the Liver (AISF): the multidisciplinary clinical approach to hepatocellular carcinoma. Dig Liver Dis 2013;45:712-723.

30 Burrel M, Reig M, Forner A, Barrufet M, de Lope CR, Tremosini S, Ayuso C, Llovet JM, Real MI, Bruix J: Survival of patients with hepatocellular carcinoma treated by transarterial chemoembolisation (TACE) using drug eluting beads. Implications for clinical practice and trial design. J Hepatol 2012;56:1330-1335.

31 Choo SP, Tan WL, Goh BK, Tai WM, Zhu AX: Comparison of hepatocellular carcinoma in Eastern versus Western populations. Cancer DOI 10.1002/cncr.30237.

32 Lanza E, Donadon M, Poretti D, Pedicini V, Tramarin M, Roncalli M, Rhee H, Park YN, Torzilli G: Transarterial therapies for hepatocellular carcinoma. Liver Cancer 2016;6:27-33.

33 GLOBOCAN Cancer Fact Sheet. Liver Cancer Estimated Incidence, Mortality and Prevalence Worldwide in 2012. http://globocan.iarc.fr/Pages/fact_sheets_cancer.aspx\# (accessed September 13, 2017).

34 Yau T, Tang VY, Yao TJ, Fan ST, Lo CM, Poon RT: Development of Hong Kong Liver Cancer staging system with treatment stratification for patients with hepatocellular carcinoma. Gastroenterology 2014;146:1691-1700.

35 Osaki Y, Nishikawa H: Treatment for hepatocellular carcinoma in Japan over the last three decades: our experience and published work review. Hepatol Res 2015;45:59-74.

36 Takayasu K, Arii S, Ikai I, Omata M, Okita K, Ichida T, Matsuyama Y, Nakanuma Y, Kojiro M, Makuuchi M, Yamaoka Y: Prospective cohort study of transarterial chemoembolization for unresectable hepatocellular carcinoma in 8,510 patients. Gastroenterology 2006;131:461-469.

37 Yan X, Fu X, Cai C, Zi X, Yao H, Qiu Y: Validation of models in patients with hepatocellular carcinoma: comparison of Hong Kong Liver Cancer with Barcelona Clinic Liver Cancer staging system in a Chinese cohort. Eur J Gastroenterol Hepatol 2015;27:1180-1186.

38 Adhoute X, Penaranda G, Bronowicki JP, Raoul JL: Usefulness of the HKLC versus the BCLC staging system in a European HCC cohort. J Hepatol 2015;62:492-493.

39 Ogasawara S, Chiba T, Ooka Y, Kanogawa N, Motoyama T, Suzuki E, Tawada A, Nagai K, Nakagawa T, Sugawara T, Hanaoka H, Kanai F, Yokosuka O: A randomized placebo-controlled trial of prophylactic dexamethasone for transcatheter arterial chemoembolization. Hepatology DOI 10.1002/hep.29403.

40 Piscaglia F, Tovoli F, Pini P, Salvatore V: A new horizon in the prevention of the postembolization syndrome after transcatheter arterial chemoembolization for hepatocellular carcinoma. Hepatology DOI: 10.1002/ hep.29517.

41 Raoul JL, Sangro B, Forner A, Mazzaferro V, Piscaglia F, Bolondi L, Lencioni R: Evolving strategies for the management of intermediate-stage hepatocellular carcinoma: available evidence and expert opinion on the use of transarterial chemoembolization. Cancer Treat Rev 2011;37:212-220. 
42 Dufour JF, Bargellini I, De Maria N, De Simone P, Goulis I, Marinho RT: Intermediate hepatocellular carcinoma: current treatments and future perspectives. Ann Oncol 2013;24(suppl 2):ii24-ii29.

43 Raoul JL, Gilabert M, Piana G: How to define transarterial chemoembolization failure or refractoriness: a European perspective. Liver Cancer 2014;3:119-124.

44 Kadalayil L, Benini R, Pallan L, O’Beirne J, Marelli L, Yu D, Hackshaw A, Fox R, Johnson P, Burroughs AK, Palmer DH, Meyer T: A simple prognostic scoring system for patients receiving transarterial embolisation for hepatocellular cancer. Ann Oncol 2013;24:2565-2570.

45 Ogasawara S, Chiba T, Ooka Y, Kanogawa N, Motoyama T, Suzuki E, Tawada A, Azemoto R, Shinozaki M, Yoshikawa M, Yokosuka O: A prognostic score for patients with intermediate-stage hepatocellular carcinoma treated with transarterial chemoembolization. PLoS One 2015;10:e0125244.

46 Sieghart W, Hucke F, Pinter M, Graziadei I, Vogel W, Muller C, Heinzl H, Trauner M, Peck-Radosavljevic M: The ART of decision making: retreatment with transarterial chemoembolization in patients with hepatocellular carcinoma. Hepatology 2013;57:2261-2273.

47 Arizumi T, Ueshima K, Iwanishi M, Minami T, Chishina H, Kono M, Takita M, Kitai S, Inoue T, Yada N, Hagiwara S, Ida H, Minami Y, Sakurai T, Nishida N, Kitano M, Kudo M: Evaluation of ART scores for repeated transarterial chemoembolization in Japanese patients with hepatocellular carcinoma. Oncology 2015;89(suppl 2):4-10.

48 Okuda K, Ohtsuki T, Obata H, Tomimatsu M, Okazaki N, Hasegawa H, Nakajima Y, Ohnishi K: Natural history of hepatocellular carcinoma and prognosis in relation to treatment. Study of 850 patients. Cancer 1985;56: 918-928.

49 A new prognostic system for hepatocellular carcinoma: a retrospective study of 435 patients: the Cancer of the Liver Italian Program (CLIP) investigators. Hepatology 1998;28:751-755.

50 Prospective validation of the CLIP score: a new prognostic system for patients with cirrhosis and hepatocellular carcinoma. The Cancer of the Liver Italian Program (CLIP) Investigators. Hepatology 2000;31:840-845.

51 Kudo M, Chung H, Osaki Y: Prognostic staging system for hepatocellular carcinoma (CLIP score): its value and limitations, and a proposal for a new staging system, the Japan Integrated Staging Score (JIS score). J Gastroenterol 2003;38:207-215.

52 Liu PH, Hsu CY, Lee YH, Su CW, Hsia CY, Huang YH, Chiou YY, Lin HC, Huo TI: Hong Kong Liver Cancer Staging System is associated with better performance for hepatocellular carcinoma: special emphasis on viral etiology. Medicine (Baltimore) 2015;94:e1772.

53 Kim KM, Sinn DH, Jung SH, Gwak GY, Paik YH, Choi MS, Lee JH, Koh KC, Paik SW: The recommended treatment algorithms of the BCLC and HKLC staging systems: does following these always improve survival rates for HCC patients? Liver Int 2016;36:1490-1497.

54 Bolondi L, Burroughs A, Dufour JF, Galle PR, Mazzaferro V, Piscaglia F, Raoul JL, Sangro B: Heterogeneity of patients with intermediate (BCLC B) hepatocellular carcinoma: proposal for a subclassification to facilitate treatment decisions. Semin Liver Dis 2012;32:348-359.

55 Arizumi T, Ueshima K, Iwanishi M, Minami T, Chishina H, Kono M, Takita M, Kitai S, Inoue T, Yada N, Hagiwara S, Ida H, Minami Y, Sakurai T, Kitano M, Nishida N, Kudo M: Validation of a modified substaging system (Kinki criteria) for patients with intermediate-stage hepatocellular carcinoma. Oncology 2015;89(suppl 2):47-52.

56 Kohla MA, Abu Zeid MI, Al-Warraky M, Taha H, Gish RG: Predictors of hepatic decompensation after TACE for hepatocellular carcinoma. BMJ Open Gastroenterol 2015;2:e000032.

57 Golfieri R, Renzulli M, Mosconi C, Forlani L, Giampalma E, Piscaglia F, Trevisani F, Bolondi L: Hepatocellular carcinoma responding to superselective transarterial chemoembolization: an issue of nodule dimension? J Vasc Interv Radiol 2013;24:509-517.

58 Adhoute X, Penaranda G, Naude S, Raoul JL, Perrier H, Bayle O, Monnet O, Beaurain P, Bazin C, Pol B, Folgoc GL, Castellani P, Bronowicki JP, Bourliere M: Retreatment with TACE: the ABCR SCORE, an aid to the decisionmaking process. J Hepatol 2015;62:855-862.

59 Terzi E, Terenzi L, Venerandi L, Croci L, Renzulli M, Mosconi C, Allegretti G, Granito A, Golfieri R, Bolondi L, Piscaglia F: The ART score is not effective to select patients for transarterial chemoembolization retreatment in an Italian series. Dig Dis 2014;32:711-716.

60 Kudo M, Arizumi T, Ueshima K: Assessment for retreatment (ART) score for repeated transarterial chemoembolization in patients with hepatocellular carcinoma. Hepatology 2014;59:2424-2425.

61 Kloeckner R, Pitton MB, Dueber C, Schmidtmann I, Galle PR, Koch S, Worns MA, Weinmann A: Validation of clinical scoring systems ART and ABCR after transarterial chemoembolization of hepatocellular carcinoma. J Vasc Interv Radiol 2017;28:94-102.

62 Pinato DJ, Arizumi T, Jang JW, Allara E, Suppiah PI, Smirne C, Tait P, Pai M, Grossi G, Kim YW, Pirisi M, Kudo M, Sharma R: Combined sequential use of HAP and ART scores to predict survival outcome and treatment failure following chemoembolization in hepatocellular carcinoma: a multi-center comparative study. Oncotarget 2016; 7:44705-44718.

63 Arizumi T, Ueshima K, Iwanishi M, Minami T, Chishina H, Kono M, Takita M, Yada N, Hagiwara S, Minami Y, Ida H, Komeda Y, Takenaka M, Sakurai T, Watanabe T, Nishida N, Kudo M: The overall survival of patients with hepatocellular carcinoma correlates with the newly defined time to progression after transarterial chemoembolization. Liver Cancer 2017;6:227-235.

64 Ogasawara S, Chiba T, Ooka Y, Kanogawa N, Motoyama T, Suzuki E, Tawada A, Kanai F, Yoshikawa M, Yokosuka O: Efficacy of sorafenib in intermediate-stage hepatocellular carcinoma patients refractory to transarterial chemoembolization. Oncology 2014;87:330-341. 
65 Arizumi T, Ueshima K, Minami T, Kono M, Chishina H, Takita M, Kitai S, Inoue T, Yada N, Hagiwara S, Minami Y, Sakurai T, Nishida N, Kudo M: Effectiveness of sorafenib in patients with transcatheter arterial chemoembolization (TACE) refractory and intermediate-stage hepatocellular carcinoma. Liver Cancer 2015;4:253262.

66 Liu L, Chen H, Wang M, Zhao Y, Cai G, Qi X, Han G: Combination therapy of sorafenib and TACE for unresectable HCC: a systematic review and meta-analysis. PLoS One 2014;9:e91124.

67 Zhang L, Hu P, Chen X, Bie P: Transarterial chemoembolization (TACE) plus sorafenib versus TACE for intermediate or advanced stage hepatocellular carcinoma: a meta-analysis. PLoS One 2014;9:e100305.

68 Meyer T, Fox R, Ma YT, Ross PJ, James MW, Sturgess R, Stubbs C, Stocken DD, Wall L, Watkinson A, Hacking N, Evans TRJ, Collins P, Hubner RA, Cunningham D, Primrose JN, Johnson PJ, Palmer DH: Sorafenib in combination with transarterial chemoembolisation in patients with unresectable hepatocellular carcinoma (TACE 2): a randomised placebo-controlled, double-blind, phase 3 trial. Lancet Gastroenterol Hepatol 2017;2:565-575.

69 Lencioni R, Llovet JM, Han G, Tak WY, Yang J, Guglielmi A, Paik SW, Reig M, Kim DY, Chau GY, Luca A, Del Arbol LR, Leberre MA, Niu W, Nicholson K, Meinhardt G, Bruix J: Sorafenib or placebo plus TACE with doxorubicineluting beads for intermediate stage HCC: the SPACE trial. J Hepatol 2016;64:1090-1098.

70 Pecorelli A, Lenzi B, Gramenzi A, Garuti F, Farinati F, Giannini EG, Ciccarese F, Piscaglia F, Rapaccini GL, Di MM, Caturelli E, Zoli M, Borzio F, Sacco R, Cabibbo G, Felder M, Morisco F, Gasbarrini A, Baroni GS, Foschi FG, Biasini E, Masotto A, Virdone R, Bernardi M, Trevisani F: Curative therapies are superior to standard of care (transarterial chemoembolization) for intermediate stage hepatocellular carcinoma. Liver Int 2017;37:423-433.

71 Kudo M: A new era of systemic therapy for hepatocellular carcinoma with regorafenib and lenvatinib. Liver Cancer 2017;6:177-184.

72 Lee HC, Cheng A-L, Raoul J-L, Peck-Radosavljevic M, Nakajima K, Kudo M: Regional differences in transarterial chemoembolization (TACE) use in HCC: OPTIMIS interim analysis. Hepatol Int 2016;10(suppl 1):S56-S57.

73 Raoul J, Sherman M, Nadel A, Lentini G, Moscovici MM, Voliotis D, Meinhardt G, Bruix J, Llovet JM: Efficacy and safety of sorafenib (Sor) in patients (pts) with advanced hepatocellular carcinoma (HCC): subgroup analyses of the SHARP and Asia-Pacific (AP) trials by baseline (BL) transaminase (ALT/AST)/alpha-fetoprotein (AFP) and bilirubin (BIL) levels. Ann Oncol 2010;21(suppl 8):viii236-viii237.

74 Gao Q, Wang XY, Zhou J, Fan J: Heterogeneity of intermediate-stage HCC necessitates personalized management including surgery. Nat Rev Clin Oncol 2015;12:10. 